\title{
Interaction of Safety Climate and Safety Culture: A Model for Cancer Treatment Centers
}

\author{
Saeed Yari ${ }^{1}$, Mohammad Hassan Naseri², Hamed Akbari², Saeed Shahsavari ${ }^{3}$, \\ Hesam Akbari ${ }^{2 *}$
}

\begin{abstract}
Background: In health care institutions, safety culture is defined as the integrity of individual and group efforts to reduce the harms for the patients. This is possible through interactions, attitudes, and understanding of safety matters. On the other hand, one of the indicators of the safety culture is the safety climate. Objective: The aim of this study is to investigate the interaction between safety climate and safety culture using structural equation modeling in personnel of cancer treatment centers in Iran. Methods: In this study, 680 personnel of Iran's hospitals were chosen in a random manner. Demographic (9 questions), safety culture (42 questions) and safety climate (37 questions) questionnaires were filled. The data were inserted in SPSS 20 software. Descriptive statistics method and Pearson's correlation coefficient were used to describe the data and evaluate the relation between the variables, respectively. Structural equations model was developed using AMOS 22 software and fitness of the model was tested by $\chi^{2}$, RMSEA, GFI and NFI statistics. Results: The scores of safety climate and safety culture were 3.61 and 3.30, respectively, which imply that they are suiTable. The overall fitness of the model was accepTable. In this model, $\chi^{2}=8637.17$, df $=2964, \chi^{2} / \mathrm{df}=2.914$, $\mathrm{RMSEA}=0.058, \mathrm{NFI}=0.912, \mathrm{GFI}=0.907$, and $\mathrm{CFI}=0.875$. In the regression analysis, there were positive significant relationships between safety climate and safety culture, safety climate and any of its components, and safety culture and any of the components. Conclusion: It was found that the safety climate and the safety culture had a positive impact on each other; so that with increasing safety climate, the safety culture also increases, and vice versa. Also, the level of education has a positive impact on safety culture and safety climate. So appropriate training can promote both variables in cancer treatment hospitals.
\end{abstract}

Keywords: Safety culture- safety climate- patient safety- cancer treatment center- modeling

Asian Pac J Cancer Prev, 20 (3), 961-969

\section{Introduction}

In all organizations, especially those that offer people emergency services, an environment should be created, in which no harm or damage threatens the employees. So, the safety of the hospitals as the most important organization offering medical services requires special attention. A hospital needs to be a safe place for patients and the personnel (Yari, 2017; Yari et al., 2018). Safety climate is defined as a mental understanding of the personnel about organizational policies (Radzaz et al., 2013). One of the indicators of the safety culture is the safety climate, which refers to the common understanding of people about safety in the workplace (Chen et al., 2017).

\section{Safety climate}

Safety climate is widely considered as a criterion for assessment of safety level in work places (Budworth 1997). It presents an overall image of the safety situation of an organization(Huang et al., 2007). Safety climate is multi-dimensional, but there is no consensus over the aspects of the safety climate (Budworth, 1997; Chen McCabe and Hyatt, 2017). Safety climate is defined as the common image that workers have in mind about policies, processes, actions, and priorities in workplace (Zohar 1980; Griffin et al., 2000). This was first measured by Zoher (1980). It is a measurement of the current state of the organization and it is relatively unsTable based on time and place and changes due to circumstances (Lin et al., 2008). So, safety climate is highly under the influence of organizational and personal elements. It might affect safety behaviors of the personnel (Gatien, 2010). Researchers also found that the attitude of the workers regarding safety makes them search for safer environments, which in turn reduces unsafe behaviors and consequently improves safety situation (Jafari et al., 2014; Yari, 2015; Yari et al., 2018). Safety climate is defined as a psychological fundamental procedure, in which workers 
share the quality of workplace (Kim et al., 2017). Safety climate indicated that at the moment safety policies are in action and it can have a direct effect on safety behaviors of the workers. It can also predict future events (Brown et al., 1986; Yari et al., 2015; Normohammadi et al., 2016).

\section{Safety Culture}

The phrase "safety culture" was first stated by the World Atomic Energy Agency in 1986. They used it in the Chernobyl accident report to justify an organizational error and a person's impairment in performance that led to the disaster (Tabibi et al., 2011). Safety culture is a set of beliefs, norms, attitudes, roles, and social and technological methods to reduce the workers' dangerous situations (Turner et al., 1989; Pidgeon, 1991). In health care institutions, safety culture is defined as the integrity of individual and group efforts to reduce the harms for the patients. This is possible through interactions, attitudes, and understanding of safety matters (Cooper, 2000). So, safety culture is a multi-dimensional concept and it does not have one clear and precise dimension (FernándezMuñiz et al., 2007). In a positive safety culture, the culture itself creates an atmosphere, in which everything that is related to safety is considered important (P et al., 2007). Studies regarding health and safety indicate that the cause of 85 to 98 percent of unsafe behaviors that lead to accidents is weak safety culture (Jafari et al., 2015; Chen et al., 2017). Therefore, the aim of this study was to investigate the interaction of safety climate and safety culture with the use of structural equation modeling in personnel of cancer treatment centers in Iran.

\section{Literature review}

In a study performed by Idris et al., (2012) the aim was to determine a conceptual differentiation and its impact on occupational and mental health demand among Australian and Malaysian communities, and it was found that the level of cognitive safety climate was significantly lower than the physical safety climate in both countries. This is an evidence of global lack of attention to mental health in working environments. Pousette et al., (2017) showed that the patient's safety climate and the occupational safety climate are very positive at the unit level, and organizational processes are important for the development of both types of organizational climate. So, interventions must be planned in the way, in which both patient as well as staff safeties are taken into account. Rigobello et al., (2017) helps understanding Professional perceptions of the patient's safety environment in urgent care, to assess safety culture, improve health care, reduce side effects, and improve the quality of services for patients. Clarke (2010) argued that psychological depression has important impacts on safety outcomes, such as accidents and injuries. Park et al., (2013) found out that safety accidents of the patients are under the influence of job transfer, cognitive impairment and job stress. They also suggest that reduction in job instability and a definition of job limits is required for the patients' safety.

\section{Materials and Methods}

\section{Design}

In this study, a descriptive analysis was performed on the personnel of cancer treatment centers in Iran. Here, the main variables were safety climate and safety culture, and personal and professional characteristics considered as background variables.

\section{Data gathering tools}

Data gathering tools consisted of three questionnaires as follows:

1. Demographic information questionnaire: This part consisted of 9 questions including age, gender, marital status, education, major, job title, experience in the field, experience in the unit, and salary.

2. Safety climate questionnaire: This questionnaire consisted of 37 questions in form of Likert scale with 5 alternatives (quite disagree, disagree, no idea, agree, quite agree). Question scores indicate the measured amount for every item ranging from 1 to 5 , in which 1 is unfavorable and 5 is the favorable state. This questionnaire includes 8 aspects of management commitment for safety and priority of safety matters (10 questions), the knowledge of the workers and following safety rules (7 questions), the attitude of the workers regarding safety (4 questions), cooperation of the workers and commitment to following safety (5 questions), safety of workplace (4 questions), priority of safety over products (2 questions), and neglecting dangers (2 questions). Zeidi et al., (2012) in a study through exploratory factor analysis showed that the 8 aspects of the questionnaire are able to explain 68.42 percent of the overall variance and Cronbach alpha coefficient for all the aspects and the whole of the tool was approved.

3. Safety culture questionnaire: HSOPSC questionnaire consisted of 42 questions in the form of Likert scale with 5 alternatives (quite disagree, disagree, no idea, agree, quite agree). Question scores indicate the measured amount for every item ranging from 1 to 5 , in which 1 is unfavorable and 5 is the favorable state. This questionnaire includes 12 aspects of frequency of event reporting (3 questions), overall perceptions of safety (4 questions), management expectations (4 questions), organization learning (3 questions), teamwork within units (4 questions), communication openness (3 questions), feedback and communication (3 questions), non-punitive response to error (3 questions), staffing (4 questions), management support (3 questions), teamwork across units (3 questions) and hospital and transitions (5 questions). Javad et al., (2012) distributed questionnaires between 30 members of the intended population randomly with a gap of 10 days (test-retest method) to confirm the reliability of the study (more than 0.60 ). The validity of the questionnaire was confirmed using the correlation of the dimensions of the questionnaire method (Javad et al., 2012).

\section{Sampling method}

The studied population was all the personnel of cancer treatment centers in Iran. Here, the logic was selecting 10 
samples for each variable according to James Stevens' proposal. He assumes that 10 to 15 items are required for each predictor variable, multiple regression analysis with the standard method of the least standard squares, as well as verifiable factor analysis models and structural equations (Chin et al., 2008; Byrne, 2013). Based on this, 720 people were selected according to simple random sampling. Finally, 680 questionnaires were filled and analyzed.

\section{Data gathering method}

The criteria for entering the participants in the research were being volunteer and honest. Then, they were assured that their answers were confidential and the data would be collected, evaluated and reported regardless of the names. Data gathering method was interview by the research team.

\section{Conceptual Model}

The aim of this study was to investigate the interaction of safety climate and safety culture with the use of structural equation modeling in personnel of cancer treatment centers in Iran. This model makes it possible to study outside hidden variables (independent) and inside hidden variable simultaneously. The primary model and conceptual models are presented in Figure 1.

\section{Data analysis}

The gathered data were entered into SPSS 20 software. Descriptive statistics method was used to describe them. Also, Pearson's correlation coefficient was used to evaluate the relation between the variables. Structural Equation Modeling, which is a type of multivariate analysis, was used to evaluate the relation between safety climate and safety culture (Yari et al., 2018). SEM is a strong, general multi-variable analysis technique, based on multi-variable regression or developed from general linear model (to make it more precise), which allows researchers to test a series of regression equations simultaneously and study the relationship between different variables concurrently (Reisinger et al., 1999; Alavi, 2013; Zaira et al., 2017). Structural equations model was developed using AMOS 22 software. The fitness of the model was controlled by $\chi^{2}$ and the root mean squares estimated error
(RMSEA) was evaluated. The amount of $\chi^{2}$ ration to a degree of freedom smaller than $3\left(\chi^{2} / \mathrm{d} f<3\right)$ was chosen as a criteria to fit the model. RMSEA $<0.08$ was another criteria for the fitness of rhea model. Also, Goodness of fit index (GFI), Comparative fit index, and Normal fit index (NFI) were used.

\section{Results}

\section{Sample characteristics}

In the current study, among 680 participants, 422 were men (\%62), 258 were women (\%38), 145 (\%21.3) were single, $535(\% 78.7)$ were married, $104(\% 15.3)$ worked in the operation room, $104(\% 15.3)$ were anesthesiologists, $314(\% 46)$ were nurses, and $158(\% 24)$ had other positions. Also, majority of the participants (\%24) aged 31- 35 and $\% 26.7$ of them had 6-10 years of professional experience.

\section{Correlation coefficient}

Pearson's correlation coefficient for the measured variables is presented in Table 2 . Safety climate is directly related to the components of safety climate (commitment, knowledge, attitude, participation, safety at work, personal readiness, priorities, and ignorance). Also, safety culture is directly related to the components of the safety culture (frequency of event reporting, overall perceptions of safety, management expectations, organization learning, teamwork within units, communication openness, feedback and communication, non-punitive response to error, staffing, management support, teamwork across units and hospital and transitions). The mean of commitment, knowledge, attitude, participation, safety at work, personal readiness, priorities, ignorance, frequency of event reporting, overall perceptions of safety, management expectations, organization learning, teamwork within units, communication openness, feedback and communication, non-punitive response to error, staffing, management support, teamwork across units and hospital and transitions were 3.54, 3.60, 3.60, $3.72,3.78,3.58,3.59,3.46,3.48,3.54,3.50,3.64,3.68$, $3.56,2.47,3.04,3.37,3.27,2.97$ and 2.99 respectively. Also the average safety climate and safety culture were 3.61 and 3.30 respectively, both of which are appropriate.

In this study, gender $(\mathrm{p}<0.003)$, education $(\mathrm{p}=0.007)$,

Table 1. Demographic Properties of Participants

\begin{tabular}{llccllcc}
\hline Variable & Group & Frequency & Percentage & Variable & Group & Frequency & Percentage \\
\hline Sex & Male & 422 & 62 & Age & Under 30 & 150 & 22 \\
& Female & 258 & 38 & & Between 31 and 35 & 163 & 24 \\
Work experience & Less than 5 & 177 & 26 & & Between 36 and 40 & 122 & 18 \\
& Between 6 and 10 & 182 & 26.7 & & Between 41 and 45 & 82 & 12 \\
& Between 11 and 15 & 86 & 12.7 & & Between 46 and 50 & 86 & 12.7 \\
& Between 16 and 20 & 100 & 14.7 & & Above 50 & 77 & 11.3 \\
& Between 21 and 25 & 72 & 10.7 & Positions & Operating room & 104 & 15.3 \\
& Between 26 and 30 & 50 & 7.3 & & Anesthesia & 104 & 15.3 \\
Marital status & Above 30 & 13 & 2 & & Nursing & 314 & 46 \\
& Single & 145 & 21.3 & & Others & 158 & 23.3
\end{tabular}




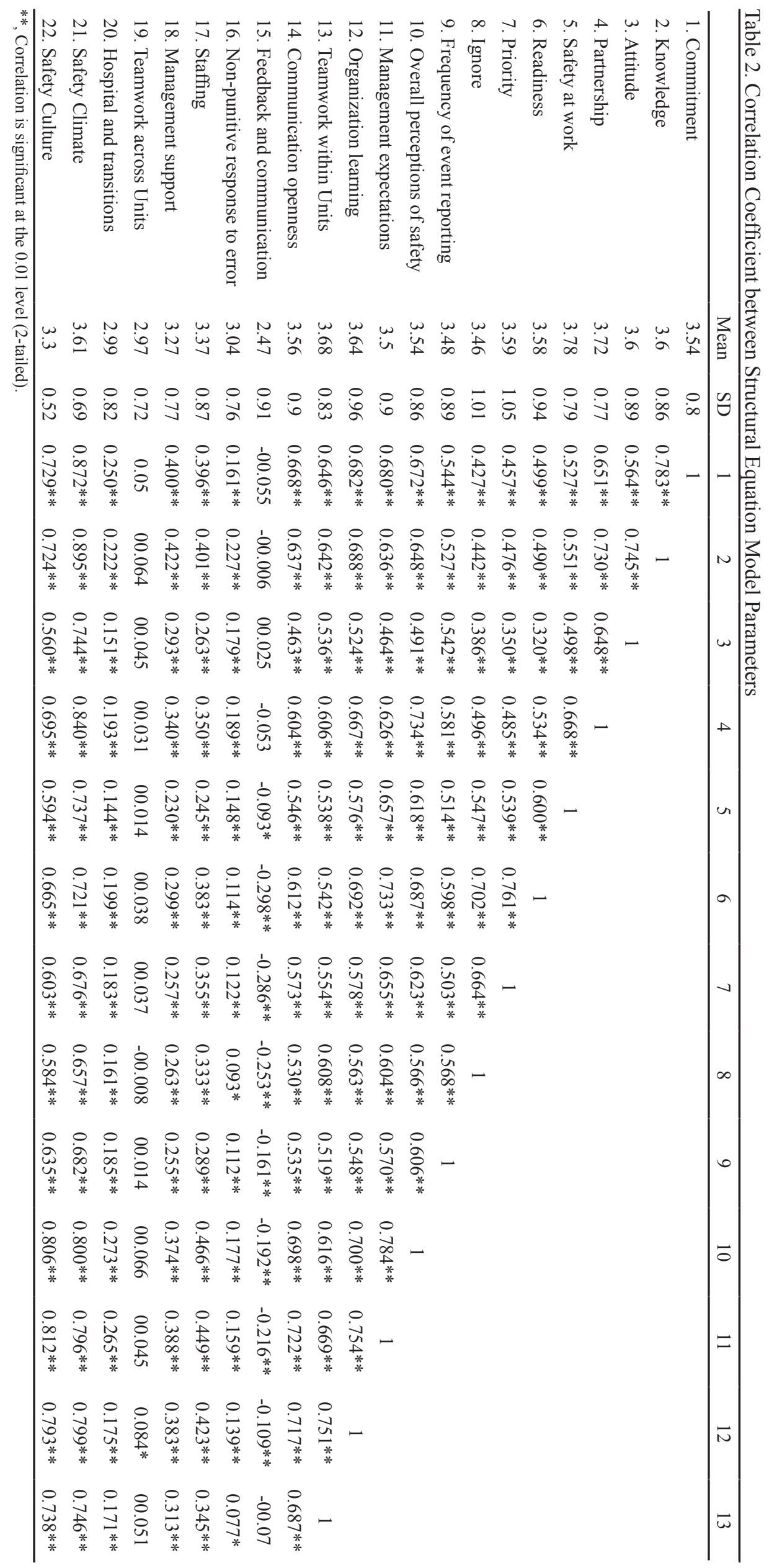




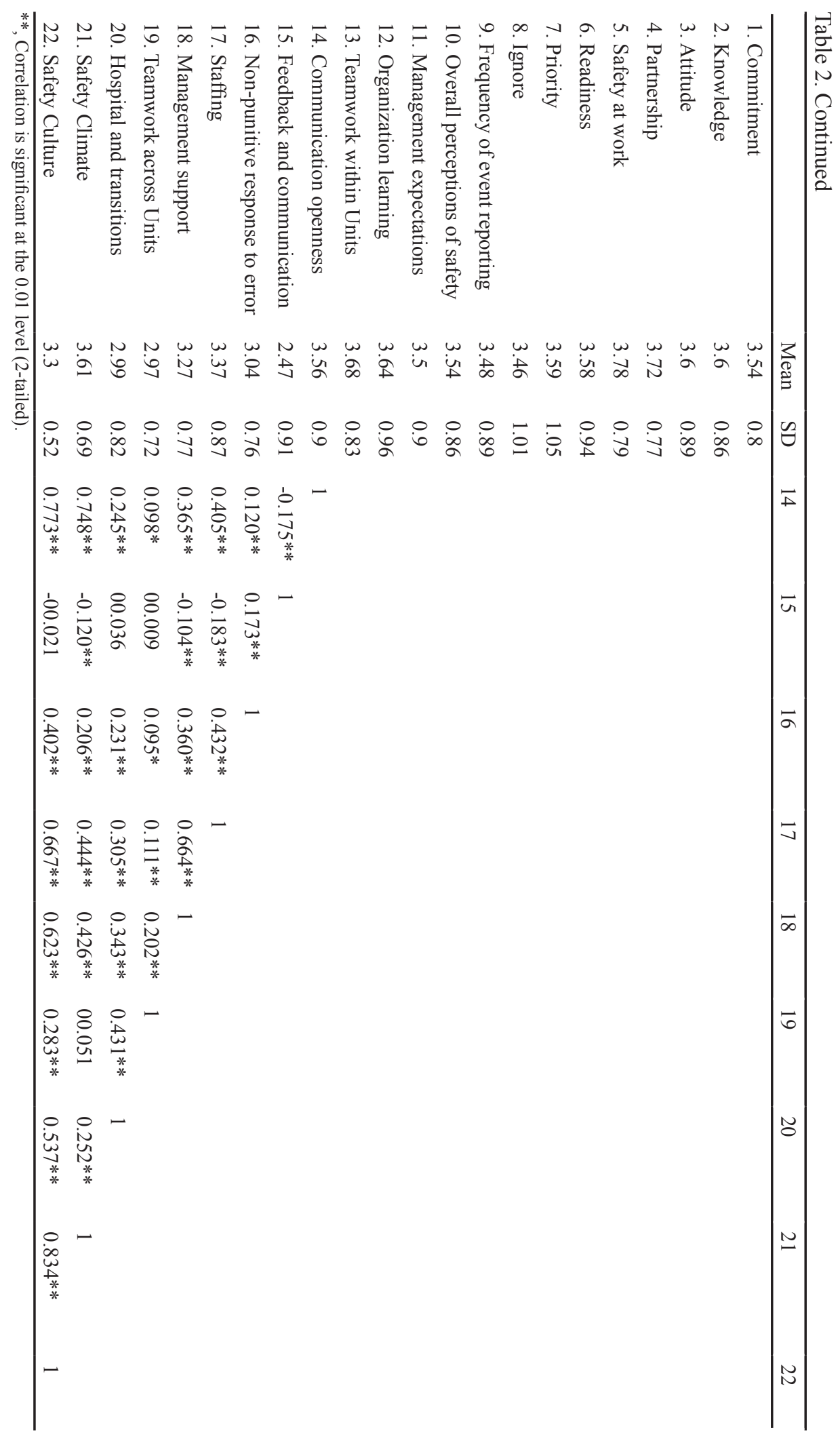

and position $(\mathrm{p}=0.042)$ were all significant in the safety climate. Also education $(\mathrm{p}=0.017)$ was significant in the safety culture.

\section{Structural equation modeling}

Figure 2 shows the coefficients of the standard estimation of the structural equation model. All paths are at a significant level. However, according to the values obtained for fitting indexes in Table $3: \chi^{2} / \mathrm{df}$, GFI, CFI and
NFI are not within the defined range. Therefore, it was concluded that fitting the model obtained at this stage does not indicate a good fit. So the model was corrected for a better fitting. These modifications were implemented in the proposed model and the results of the fitting indexes improved (Figure 2). Finally, the overall fitting of the model was accepTable. In this model, $\chi^{2}=8637.17$, df $=2964, \chi^{2} / \mathrm{df}=2.914, \mathrm{RMSEA}=0.058, \mathrm{NFI}=0.912$, $\mathrm{GFI}=0.907$, and $\mathrm{CFI}=0.875$. 


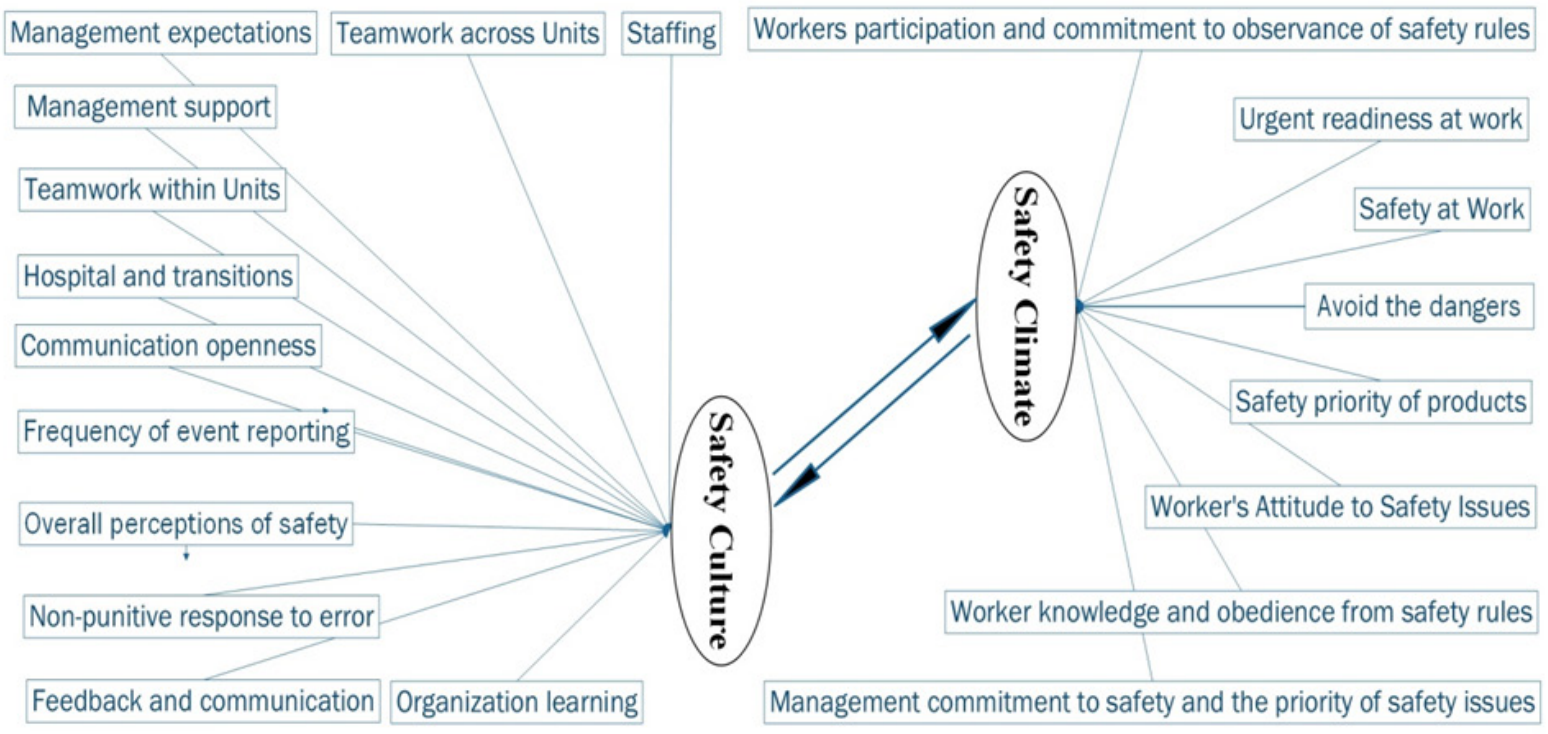

Figure 1. The Conceptual Model between Safety Climate and Safety Culture

Table 3. Comparison of Fitness Indices in Conceptual Model and Proposed Model

\begin{tabular}{lccc}
\hline proposed model & conceptual model & Limit & Index \\
\hline 2.914 & 3.251 & Less than 3 & $\chi 2 / \mathrm{df}$ \\
0.907 & 0.862 & Higher than 9.0 & GFI \\
0.058 & 0.063 & Less than 08/0 & RMSEA \\
0.875 & 0.827 & Higher than 9.0 & CFI \\
0.912 & 0.848 & Higher than 9.0 & NFI \\
\hline
\end{tabular}

In the regression analysis, safety climate with safety culture, safety climate with any of its components, and safety culture with any of its components had significant relationships (Table 4). Figure 2 shows the relationships between the components of the structural equations model. Safety climate can be directly related to safety culture $(\beta=0.994, p<0.001)$. It is also directly related to commitment $(\beta=0.818, \mathrm{p}<0.001)$, knowledge $(\beta=0.829$, $\mathrm{p}<0.001)$, attitude $(\beta=0.672, \mathrm{p}<0.001)$, participation

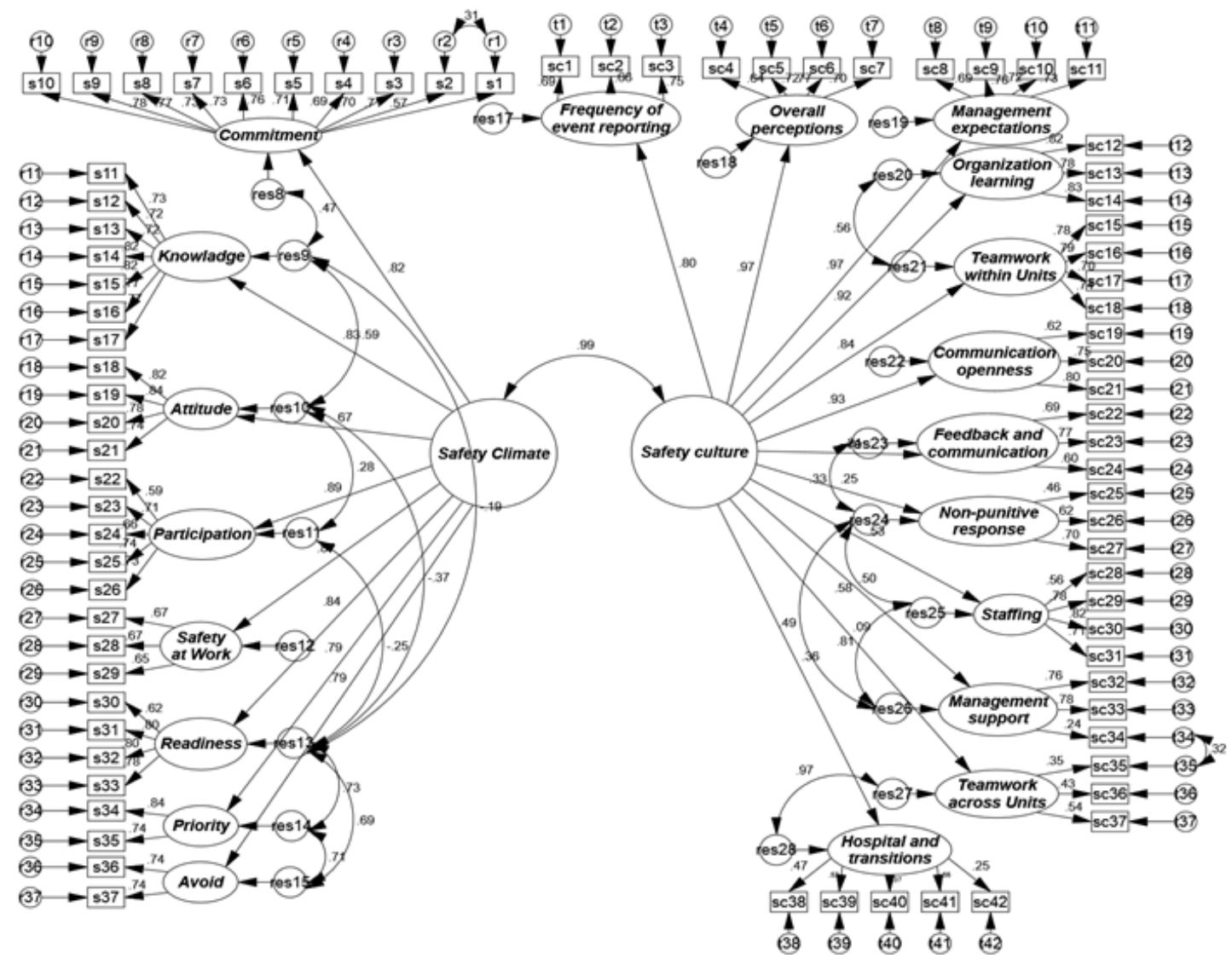

Figure 2. The Paths between the Components in the Final Model 
Table 4. Regression Weights in the Parameters of the Structural Equation Model in the Final Model

\begin{tabular}{|c|c|c|c|c|c|c|c|}
\hline & & & Standardized Estimate & Nonstandardized Estimate & SE & $\mathrm{CR}$ & P-value \\
\hline Safety Climate & $<-->$ & Safety Culture & 0.994 & 0.288 & 0.029 & 9.782 & $* * *$ \\
\hline Commitment & $--->$ & Safety Climate & 0.818 & 1 & & & \\
\hline Overall perceptions & $--->$ & Safety Culture & 0.97 & 1.072 & 0.08 & 13.333 & $* * *$ \\
\hline Knowladge & $--->$ & Safety Climate & 0.829 & 1.526 & 0.115 & 13.241 & $* * *$ \\
\hline Frequency of event reporting & $--->$ & Safety Culture & 0.798 & 1 & & & \\
\hline Management expectations & $--->$ & Safety Culture & 0.968 & 1.028 & 0.074 & 13.966 & $* * *$ \\
\hline Teamwork within Units & $--->$ & Safety Culture & 0.836 & 1.006 & 0.072 & 13.925 & $* * *$ \\
\hline Communication openness & $--->$ & Safety Culture & 0.926 & 0.909 & 0.072 & 12.645 & $* * *$ \\
\hline Feedback and communication & $--->$ & Safety Culture & -0.205 & -0.251 & 0.058 & -4.35 & $* * *$ \\
\hline Non-punitive response & $--->$ & Safety Culture & 0.245 & 0.174 & 0.038 & 4.542 & $* * *$ \\
\hline Staffing & $--->$ & Safety Culture & 0.535 & 0.51 & 0.055 & 9.245 & $* * *$ \\
\hline Management support & $--->$ & Safety Culture & 0.497 & 0.609 & 0.064 & 9.548 & $* * *$ \\
\hline Organization learning & $--->$ & Safety Culture & 0.918 & 1.257 & 0.083 & 15.123 & $* * *$ \\
\hline Teamwork across Units & $--->$ & Safety Culture & 0.095 & 0.08 & 0.051 & 1.583 & 0.113 \\
\hline Hospital and transitions & $--->$ & Safety Culture & 0.361 & 0.313 & 0.072 & 4.376 & $* * *$ \\
\hline Safety at Work & $--->$ & Safety Climate & 0.867 & 1.299 & 0.11 & 11.808 & $* * *$ \\
\hline Readiness & $--->$ & Safety Climate & 0.842 & 1.236 & 0.107 & 11.499 & $* * *$ \\
\hline Priority & $--->$ & Safety Climate & 0.791 & 1.479 & 0.123 & 12.03 & $* * *$ \\
\hline Ignore & $--->$ & Safety Climate & 0.79 & 1.493 & 0.125 & 11.971 & $* * *$ \\
\hline Attitude & $--->$ & Safety Climate & 0.672 & 1.296 & 0.11 & 11.747 & $* * *$ \\
\hline Participation & $--->$ & Safety Climate & 0.888 & 1.138 & 0.101 & 11.279 & $* * *$ \\
\hline
\end{tabular}

***, Correlation is significant at the 0.001 level (2-tailed).

$(\beta=0.888, p<0.001)$, safety at work $(\beta=0.867, p<0.001)$, personal readiness $(\beta=0.842, p<0.001)$, and priority $(\beta=0.791, p<0.001)$. Also, safety culture, except teamwork across units $(\beta=0.095, \mathrm{p}<0.113)$ component, is directly related to frequency of event reporting $(\beta=0.798$, $\mathrm{p}<0.001)$, overall perceptions of safety $(\beta=0.970$, $\mathrm{p}<0.001)$, management expectations $(\beta=0.968, \mathrm{p}<0.001)$, organization learning $(\beta=0.918, \mathrm{p}<0.001)$, teamwork within units $(\beta=0.836, p<0.001)$, communication openness $(\beta=0.926, p<0.001)$, non-punitive response to error $(\beta=0.245, p<0.001)$, staffing $(\beta=0.535, p<0.001)$, management support $(\beta=0.497, p<0.001)$, and hospital and transitions $(\beta=0.361, p<0.001)$. Dimension only has a significant and negative relationship with the feedback and communication $(\beta=-0.205, \mathrm{p}<0.001)$.

According to the structural equation model, standard and non-standard coefficients of the final model, and the significance level between variables and factors affecting it, are presented in the Table 4.

\section{Discussion}

Mahrous (2018) research suggests that there is a strong need to improve and enhance existing policies to improve the patient safety culture in hospitals. In this case, developing strong managerial skills to promote a free counseling environment and administrative knowledge will help improve the patient safety culture. In a study by Kiaei et al., (2016) with HSOPSC questionnaire in Iran's hospitals, it was concluded that organizational learning in the hospitals was acceptable and the studied hospitals required safety-based programs and support from senior managers to improve the safety culture of the patients. Dollard et al., (2012) states that the safety climate can reduce job stress as an organizational feature and a proper climate enables the personnel to do their job. According to López-Liria et al., (2017), the results of the safety culture assessment questionnaires may be helpful in evaluating the importance of patient safety in organizations in order to make conversations about mistakes and create a learning environment and a willingness to improve health care. The results of the Petitta et al., (2017) study show that there is a complex relationship between safety culture and safety climate, which suggests that organizations with certain safety cultures may develop more (or less) positive safety climate. This study also confirmed the results of previous studies, so that safety climate with safety culture had a significant and positive relationship. In a study done by Zarei et al., (2016) in medical organizations of Iran they concluded that there is a significant relationship between safety climate, unit type, job satisfaction, job interests, and stress. The results of structural equation modeling support a negative correlation between job burnout and safety climate. Alqattan et al., (2018) shows that patient safety varies across countries, professional groups, and age groups, and should consider these variables when planning or evaluating patient safety. Vierendeels et al., (2018) in a study proposed a model titled TEAM that offered a clear view of the safety culture in an organization and proved how different safety factors and the components of safety culture are connected in a cycle. Omidi et al., (2019) and colleagues introduced the ANFIS algorithm for modeling the prediction of a patient's safety culture at healthcare centers. In the present study it was also found 
that the variables of gender, education and position have a significant effect on the safety climate and the level of education has a significant impact on the safety culture. Huang et al., (2018) performed a study regarding the importance of the safety culture of the patients from the viewpoint of the doctors and nurses. He found that there are different attitudes about safety of patients from the point of view of doctors and nurses. These results enable hospital managers to improve the safety culture of the patients. Kim et al., (2018) addresses the importance of safety climate and psychological elements like job stress of the workers. du Pisanie et al., (2018) states that the development of a safety culture can be changed through safety education, dedicated teams, behavioral interventions and culture of enforcement support; howeve, it is a difficult process. In a study conducted by Chen et al., (2017) it was found out that promoting a positive safety climate and creating educational programs could improve the safety performance of an organization due to improved mental health of employees, especially after traumas. Akbary et al., (2015) found that all aspects of the patient's safety culture are lower than accepTable level and require a huge improvements in hospitals. In a study by Leonard et al., (2018) in radiation therapy, it became clear that healthcare professionals in the radiation therapy sector felt positive about the patient's safety. HSPSC has been successfully applied to radiotherapy departments and has provided valuable insight into areas of potential improvement such as teamwork in units, staffing, and service delivery. Managers and policymakers can use this assessment tool to improve efforts focused on the patient's safety culture.

In conclusion, it was found that the safety climate and the safety culture had a positive impact on each other, So that, with increasing safety climate, the safety culture also increases, and vice versa. Moreover, the level of education has a positive impact on safety culture and safety climate. So, appropriate training can promote both variables in cancer treatment hospitals.

\section{Suggestions}

- Due to the increased awareness, safety culture and safety climate are also increased; it is recommended that hospital managers give appropriate safety training on the agenda.

- To improve the level of patient's safety in hospitals, occupational stress must be controlled and safety climate and safety culture should be increased.

- It is recommended these variables to be used to establish a patient's safety management (PSM (system in hospitals.

- It is recommended to perform further studies in this field, with appropriate interventions.

Limitations of the study

- Lack of a proper understanding about the questions of the questionnaires. To deal with this problem data were collected by interviewing.

- Refusal of participants to answer the questions correctly. To deal with this problem, all participants in the study were assured that all responses will be kept confidential.

\section{Acknowledgments}

This manuscript is the result of a research project with the code of ethics Ir.bmsu.rec.1397.225 at Baqiyatallah University of Medical Sciences. We also thank all the professors, students and other people who helped us at this study, especially participated people.

\section{References}

Akbary R, Zarei E, Gholami A, Mousavi H (2015). A survey of patient safety culture: A tool for improving patient safety in healthcare providers service organizations. Iran Occup Health, 12, 76-88.

Alavi M (2013). Structural equation modeling (SEM) in health sciences education researches: an overview of the method and its application. Iran J Med Edu, 13, 519-30.

Alqattan H, Cleland J, Morrison Z (2018). An evaluation of patient safety culture in a secondary care setting in Kuwait. J Taibah Univ Med Sci, 13, 272-80.

Brown R, Holmes H (1986). The use of a factor-analytic procedure for assessing the validity of an employee safety climate model. Accid Anal Prev, 18, 455-70.

Budworth N (1997). The development and evaluation of a safety climate measure as a diagnostic tool in safety management. IOSH J, 1, 19-29.

Byrne BM (2013). Structural equation modeling with LISREL, PRELIS, and SIMPLIS: Basic concepts, applications, and programming, Psychology Press.

Chen Y, McCabe B, Hyatt D (2017). Impact of individual resilience and safety climate on safety performance and psychological stress of construction workers: A case study of the Ontario construction industry. J Safety Res, 61, 167-76.

Chin WW, Peterson RA, Brown SP (2008). Structural equation modeling in marketing: Some practical reminders. J Marketing Theory Pract, 16, 287-98.

Clarke S (2010). An integrative model of safety climate: Linking psychological climate and work attitudes to individual safety outcomes using meta-analysis. J Occup Organ Psychol, 83, 553-78.

Cooper M (2000). Towards a model of safety culture. Saf Sci, 36, 36-111.

Dollard MF, Tuckey MR, Dormann C (2012). Psychosocial safety climate moderates the job demand-resource interaction in predicting workgroup distress. Accid Anal Prev, 45, 694-704.

Fernández-Muñiz B, Montes-Peón JM, Vazquez-Ordas CJ (2007). Safety culture: Analysis of the causal relationships between its key dimensions. J Safety Res, 38, 627-41.

Gatien B (2010). An investigation into the relationship between perceptions of safety climate and organizational justice.

Griffin MA, Neal A (2000). Perceptions of safety at work: a framework for linking safety climate to safety performance, knowledge, and motivation. J Occup Health Psychol, 5, 347.

Huang CH, Wu HH, Lee YC (2018). The perceptions of patient safety culture: A difference between physicians and nurses in Taiwan. Appl Nurs Res, 40, 39-44.

Huang YH, Chen JC, DeArmond S, Cigularov K, Chen PY (2007). Roles of safety climate and shift work on perceived injury risk: A multi-level analysis. Accid Anal Prev, 39, 1088-96.

Idris MA, Dollard MF, Coward J, Dormann C (2012). Psychosocial safety climate: Conceptual distinctiveness and effect on job demands and worker psychological health. Saf Sci, 50, 19-28. 
Jafari MJ, Gharari M, Kalantari S, et al (2015). The influence of safety training on improvement in safety climate in construction sites of a firm. Safety Promot Inj Prev, 2, 257-64.

Jafari MJ, Sadighzadeh A, Sarsangi V, Zaeri F, Yegani F (2014). Safety climate survey in iran's uranium mines in 2013. Safety Promot Inj Prev, 2, 148-54.

Javad M, Amin G, Mahbobe M, et al (2012). Validation of Farsi version of hospital survey on patient Safety culture questionnaire, using confirmatory factor analysis method. Hosp J, 11.

Kiaei MZ, Ziaee A, Mohebbifar R, et al (2016). Patient safety culture in teaching hospitals in Iran: assessment by the hospital survey on patient safety culture (HSOPSC). JHMI, 3, 51-6.

Kim KJ, Yoo MS, Seo EJ (2018). Exploring the influence of nursing work environment and patient safety culture on missed nursing care in Korea. Asian Nurs Res, 12, 121-6.

Kim KW, Park SJ, Lim HS, Cho HH (2017). Safety climate and occupational stress according to occupational accidents experience and employment type in shipbuilding industry of korea. Saf Health Work, 8, 290-5.

Leonard S, Donovan AO (2018). Measuring safety culture: Application of the hospital survey on patient safety culture to radiation therapy departments worldwide. Pract Radiat Oncol, 8, 17-26.

Lin SH, Tang WJ, Miao JY, Wang ZM, Wang PX (2008). Safety climate measurement at workplace in China: A validity and reliability assessment. Safety $S c i, 46,1037-46$.

López-Liria R, Rocamora-Pérez P, Aguilar-Parra MJ, et al (2017). Evaluation in primary care professionals: The patient's safety culture. Procedia Soc Behav Sci, 237, 1272-6.

Mahrous MS (2018). Patient safety culture as a quality indicator for a safe health system: Experience from Almadinah Almunawwarah, KSA. J Taibah Univ Med Sci, 13, 377-83.

Mohammadi Zeidi E, Farmanbar R, Hoseyni S (2012). Assessment of psychometric properties (validity and reliability) of safety climate questionnaire: Factor analysis application. J Guilan Univ Med Sci, 21,12-21.

Nasiri P, Alizade S, Ahmadlu M (2007). Development of an effective safety culture. Islamic Azad Uni Sci Res Branch, pp 31-40.

Normohammadi M, Kakooei H, Omidi L, Yari S, Alimi R (2016). Risk assessment of exposure to silica dust in building demolition sites. Saf Health Work, 7, 251-5.

Omidi L, Akbari R, Hadavandi E, Zareid E (2019). An intelligent algorithm for assessing patient safety culture and adverse events voluntary reporting using PCA and ANFIS. Int J Risk Saf Med, 30, 1-14.

Park YM, Kim SY (2013). Impacts of job stress and cognitive failure on patient safety incidents among hospital nurses. Saf Health Work, 4, 210-5.

Petitta L, Probst TM, Barbaranelli C, Ghezzi V (2017). Disentangling the roles of safety climate and safety culture: Multi-level effects on the relationship between supervisor enforcement and safety compliance. Accid Anal Prev, 99, 77-89.

Pidgeon NF (1991). Safety culture and risk management in organizations. J Cross-Cult Psychol, 22, 129-40.

Pisanie JL, Dixon R (2018). Building a culture of safety in interventional radiology. Tech Vasc Interv Radiol, 21, 198-204.

Pousette A, Larsman P, Eklöf M, Törner M (2017). The relationship between patient safety climate and occupational safety climate in healthcare-A multi-level investigation. J Safety Res, 61, 187-98.

Radzaz NHBA, Bahari SF (2013). Psychosocial safety climate in organization: An overview of theoretical and empirical development. J Social Dev Sci, 4, 407.

Reisinger Y, Turner L (1999(. Structural equation modeling with Lisrel: application in tourism. Tourism Manage, 20, 71-88.

Rigobello MCG, Carvalho REFL, Guerreiro JM, et al (2017). The perception of the patient safety climate by professionals of the emergency department. Int Emerg Nurs, 33, 1-6.

Tabibi J, Nasiripour A, Maleki M, et al (2011). Survey of employees' safety attitude in a teaching hospital Tehran 2010. Iran Occup Health, 7, 0-5.

Turner BA, Pidgeon N, Blockley D, Toft B (1989). Safety culture: its importance in future risk management. Position paper for the second World Bank workshop on safety control and risk management, Karlstad, Sweden, pp 6-9.

Vierendeels G, Reniers G, Nunen K, Ponnet K (2018). An integrative conceptual framework for safety culture: The Egg Aggregated Model (TEAM) of safety culture. Safety Sci, 103, 323-39.

Yari S (2015). Inherent safety design in compose of urban gas station. Safety Promot Inj Prev, 3, 135-40.

Yari S (2017). Assessment of potential risk by the failure mode and effects analysis in an air conditioning equipment manufacturing company. Safety Promot Inj Prev, 5, 89-96.

Yari S, Akbari H, Gholami Fesharaki M, et al (2018). Developing a model for hospital inherent safety assessment: Conceptualization and validation. Int J Risk Saf Med, 29, $1-12$.

Yari S, Fallah Asadi A, Varmazyar S (2015). Assessment of semi-quantitative health risks of exposure to harmful chemical agents in the context of carcinogenesis in the latex glove manufacturing industry. Asian Pac J Cancer Prev, 17, 11.

Zaira MM, Hadikusumo BH (2017). Structural equation model of integrated safety intervention practices affecting the safety behaviour of workers in the construction industry. Safety Sci, 98, 124-35.

Zarei E, Khakzad N, Reniers G, Akbari R (2016). On the relationship between safety climate and occupational burnout in healthcare organizations. Safety Sci, 89, 1-10.

Zohar D (1980). Safety climate in industrial organizations: theoretical and applied implications. J Appl Psychol, 65, 96 .

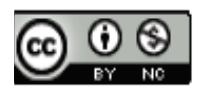

This work is licensed under a Creative Commons AttributionNon Commercial 4.0 International License. 